\title{
MACHADO, L. Z.; BORGES, A. M.; MOURA, C. P. (orgs.). A cidade e o medo. Brasilia: Verbena/Francis, p. 184, 2014.
}

\section{Nicole Kunze Rigon ${ }^{1}$}

Em novembro de 2007 ocorreu em Brasília o seminário internacional "Medo: perspectivas urbanas", no qual se reuniram na Universidade de Brasília pesquisadores de diferentes áreas que se preocuparam em pensar o fenômeno urbano sob o viés interpretativo do medo. As reflexões produzidas no âmbito deste evento resultaram nas produções que deram corpo a este volume. $\mathrm{O}$ medo é abordado aqui como um conceito difuso e em torno de sua análise gravitam temas como: violência, insegurança, políticas urbanas, subjetividades e comportamentos sociais. $\mathrm{O}$ esforço dos pesquisadores que contribuíram com capítulos para esta coletânea foi no sentido de estudar o medo na cidade sob diferentes campos interpretativos evidenciando a complexidade dos processos de construção social do medo em diferentes contextos e espaços.

Com estudos realizados na África e na América do Sul, o livro é composto por dez artigos organizados em três eixos temáticos: histórias (3), espaços (3) e políticas (4). Proponho a seguir uma breve sinopse de cada um dos artigos.

O capítulo inicial da obra e também do eixo temático histórias é de autoria de Gilberto Velho, teórico de referência para os estudos de antropologia urbana no Brasil. O autor faz uma reflexão histórica sobre o medo no país desde o tempo das invasões colonizadoras, evidenciando as transformações e deslocamentos históricos desse sentimento. Velho fala do medo associado ao modo de produção escravista, à religião católica, às religiosidades afro-brasileiras, às sociedades tradicionais; medo de períodos ditatoriais, de abuso da força e do crescimento urbano caótico e desordenado. O medo que sentem os sujeitos modernos habitantes das cidades urbanizadas é em decorrência da consolidação de um modo de vida em que, por diversos fatores, a possibilidade do crime faz parte do cotidiano. O Brasil, para Gilberto Velho, é um caso singular: "não há guerra propriamente dita, mas há um 'estado geral de perigo"” (:21) e isso implica em profundas modificações estruturais e sociais em nossas cidades.

\footnotetext{
${ }^{1}$ Universidade Federal do Rio Grande do Sul, Brasil.
} 
Vera Malaguti Batista trata do medo no contexto do Rio de Janeiro. Na transição do século XIX para o século XX, almejava-se aproximar a "cidade africana" ao ideal da "cidade europeia", típica dos centros urbanos mais desenvolvidos. Quando o assunto é insegurança em um contexto em que a memória retoma o "medo da africanidade" as questões elementares sobre direitos humanos e sociais ficam em segundo plano e os discursos do medo se transformam prontamente em políticas criminais. "Em torno do medo, a discussão política no Brasil é policizada" (: 23), afirma a autora, e as implicações disso para a configuração morfológica das cidades é o desenvolvimento de uma arquitetura penal onde a construção de muros visíveis e invisíveis que separam seus habitantes se mostra como lenitivo à sensação do medo compartilhado.

Ana Luiza Carvalho da Rocha e Cornelia Eckert refletem sobre o medo na cidade de Porto Alegre ao discorrer sobre o filme etnográfico "A cidade sitiada", produzido por elas em 2001. Em uma narrativa enriquecida com excertos do roteiro e do plano de produção, o texto fala sobre a criação de uma etnografia audiovisual que apreende a memória dos habitantes através de imagens e narrativas, retratando as "feições da crise e do medo no teatro da vida contemporânea" (: 33). O cenário é Porto Alegre, cidade cujos habitantes modificam seus hábitos coletivos para lidar com um contexto onde a criminalidade faz parte do cotidiano e assim, progressivamente se fecha em seus muros. Perpassam esta análise reflexões sobre o fenômeno da duração e sobre as transformações na paisagem urbana.

No capítulo quatro, o primeiro da seção sobre espaços, Gabriel Kessler discorre sobre a relação entre concepções sobre delito e o medo na Argentina. O autor chama a atenção para a importância de situar historicamente as representações sobre delito e aponta os desdobramentos da análise do medo como problema social. A desconfiança de longa data com as instituições de segurança e com a situação econômica do país faz com que hajam dissonâncias entre os dados estatísticos da pesquisa de vitimização e a percepção subjetiva da população em relação à segurança nas ruas. Assim, o contexto político e econômico está relacionado com o modo como os sujeitos percebem o espaço. A ideologia política influencia na percepção social da segurança e também nas definições de delito, observa o autor. Do mesmo modo, a percepção social localmente compartilhada também orienta a criação de políticas públicas. A título de problematização, Kessler lança um 
questionamento ao final do texto: sendo o medo um sentimento, haveria o Estado legitimidade para criar políticas públicas que influenciam sentimentos coletivos?

Richard Ballard aborda o crescimento de condomínios fechados na África do Sul, mais especificamente em um subúrbio a oeste de Durban. O fenômeno do deslocamento de brancos de zonas centrais e multiculturais para áreas periféricas homogeneizadas está relacionado com rastros deixados de um regime de segregação formal, o apartheid. A partir dos anos 70 a segregação formal que não era mais viável se reinventou, adquirindo novas formas. Deste modo, as comunidades cercadas construídas como resposta a uma sensação de insegurança e ao medo do crime pela população predominantemente branca, atuam na manutenção social do antigo sistema de segregação. Para dar conta do deslocamento das elites para comunidades muradas, Ballard trabalha com o conceito de semigração, que designa uma migração para uma “"cidadela autocontida' fora da qual os moradores raramente precisam aventurar-se" (: 83).

Analisar as transformações dos espaços urbanos através do crescimento dos condomínios horizontais em Goiânia foi o objetivo do estudo de Cristina Patriota de Moura. As intervenções sobre os espaços construídos são táticas que transformam os espaços urbanos em função das narrativas de vitimização (: 86). Cristina realizou sua pesquisa de campo no condomínio Campo Alegre. Como tantos outros, este condomínio foi planejado e construído para ser um espaço homogeneizado, seguro e familiar. Apesar de contar com um sofisticado aparato de segurança privada, as famílias de classes médias habitantes do Campo Alegre passaram a conviver com os perigos e mistérios das invasões a domicílios no interior do condomínio. Esses eventos que causaram polêmica entre os moradores, que no desenrolar deste drama social deixam transparecer os valores, os conflitos e os medos inerentes a este modo de vida (: 97) que coube à autora analisar.

A articulação entre os tópicos violência de gênero e medo urbano foi analisada por Lia Zanotta Machado no capítulo sete deste volume e que abre a seção temática sobre políticas. Quando o assunto é cultura do medo e da violência, Lia afirma ser imprescindível levar em consideração também as narrativas sobre os lugares do masculino e do feminino na história. $\mathrm{O}$ medo das mulheres diante da violência de gênero "é um medo assentado na longa duração da legitimação das posições masculinas hegemônicas" (: 107). Esses valores que duram nas relações entre homens e mulheres estão marcados nos códigos legais e 
jurídicos que regem o funcionamento de nossa sociedade. A crítica da autora consiste no fato de que as narrativas hegemônicas sobre medo e violência urbana silenciam as narrativas sobre as violências que acontecem no espaço privado por parceiros e familiares, fazendo com que o medo da violência de gênero ocupe uma dimensão de invisibilidade no elenco dos medos nas cidades.

Maria Stela Grossi Porto analisa como as mudanças no perfil da criminalidade e as políticas de segurança pública estão relacionadas com as definições locais sobre crime no Distrito Federal. Maria Stela chama atenção para o crescimento da violência em Brasília e, assumindo a complexidade das origens do aumento da violência, sistematiza alguns dos possíveis motivos do aumento desses índices na cidade que possui o maior número de policiais comparativamente à população (: 128). Em sua reflexão, a autora leva em consideração a questão da legitimidade que a atuação policial adquire no uso da força física. A formação de políticas públicas, pontua a autora, deve ser permeada por uma discussão sobre como a violência é percebida nos contextos em que serão implementadas as políticas e também uma discussão sobre o papel e função da polícia perante determinadas violências. As representações sociais sobre medo, violência e segurança são importantes peças a serem consideradas na construção e implementação de políticas de segurança pública.

O capítulo escrito por Mabel Grimberg versa sobre o problema do medo nos piquetes na região metropolitana de Buenos Aires, Argentina. Piquetes são ações coletivas de protesto nas quais são realizados acampamentos por desempregados de modo a trancar as ruas da cidade. O caso específico deste artigo é o dos piquetes de La Matanza, que aconteceu em 2001 e durou 18 dias. No contexto analisado pela autora, o medo figura-se como temor associado principalmente à repressão social e policial e à sabotagem por infiltrados ou espiões, como foi o caso da doação de um pacote de sal que continha soda cáustica. Há também o medo de ficar doente, de deixar as crianças sozinhas nas barracas e o medo de não voltar para casa. Em síntese, os piqueteiros vivenciam e compartilham entre si os medos e angústias associados aos movimentos sociais. 
Os movimentos sociais também foram o assunto abordado por Antonádia Monteiro Borges no último capítulo desta obra. A autora tece uma análise sobre o Landless Peoples Movement, na África do Sul, que é um movimento dos ocupantes de fazendas predominantemente negros, que buscam o direito de enterrar seus falecidos entes no interior de terras que não os pertencem e que geralmente são propriedades de homens brancos. Os corpos precisam ser enterrados juntamente de suas linhagens ancestrais e para isso é necessária uma decisão judicial que às vezes leva tempo para ser encaminhada. Antonádia fala da complexidade de tratar de um fenômeno que tem o invisível como sua dimensão constituinte, não sendo passível de ser interpretado como uma evidência concreta. Entre os manifestantes que ocupam as fazendas circula o medo da violência policial, e da violência institucional de juízes e autoridades. $\mathrm{O}$ medo em sua dimensão espiritual também é um elemento importante: há o medo de deixar de se comunicar com os ancestrais se o enterro não acontecer conforme o previsto.

O medo é um conceito difuso e fragmentado que foi analisado de diferentes formas nos capítulos que compõem esta obra. Seja como narrativa, como elemento constitutivo da imagem das cidades, como problema social, ou como emoção, o medo adquire diferentes configurações em relação ao referencial com que é pensado. Por ser subjacente às questões urbanas e por possuir importantes implicações na sociedade, o medo é um potente objeto para os estudos em ciências sociais com reflexões sobre a cidade. Devido a multiplicidade de aproximações possíveis ao tema, também pode ser assunto de interesse a outros campos disciplinares como arquitetura e urbanismo, psicologia social, direito e políticas públicas, bem como ao público em geral interessado em explorar sentidos atribuídos à experiência urbana diária.

Recebido em: 20/10/2017. Aprovado em: 15/11/2017. 